04.1;13.1

\title{
Волноводный СВЧ-плазмотрон атмосферного давления с суммированием мощности в зоне формирования плазмы
}

\author{
(C) И.Н. Антонов, В.В. Комаров ", А.Н. Пименов \\ Саратовский государственный технический университет им. Гагарина Ю.А., Саратов, Россия \\ ฯ E-mail: vyacheslav.komarov@gmail.com
}

Поступило в Редакцию 2 апреля 2021 г.

В окончательной редакции 8 июня 2021 г.

Принято к публикации 9 июня 2021г.

\begin{abstract}
Рассматривается конструкция плазмотрона атмосферного давления на прямоугольном волноводе с двусторонним подводом СВЧ-энергии в область взаимодействия. Показано, что использование двух магнетронных источников позволяет получать устойчивый разряд в плазмотроне, обеспечивая непрерывный ввод мощности в поток газа. Представлены результаты исследований рабочих режимов СВЧ-плазмотрона, доказывающие его преимущества перед аналогами.
\end{abstract}

Ключевые слова: газоразрядная плазма, СВЧ-излучение, плазмотрон, разряд.

DOI: 10.21883/PJTF.2021.18.51471.18801

СВЧ-плазменное напыление, как известно [1,2], обладает уникальными возможностями соединения разнородных материалов в результате разогрева и диспергирования капель расплава одного из них и соударения со слабо нагретой поверхностью другого. Этот метод позволяет получать покрытия из различных материалов на керамических подложках без значительного изменения свойств основы. Однако в ряде случаев покрытия, выполненные с помощью этой технологии, уступают по прочности известным типам газотермических покрытий. Проведение химических реакций в высокотемпературной среде плазмы лежит в основе нового направления физической химии и химической технологии - плазмохимии [3].

В плазме из-за появления высокореакционных частиц и излучения возникают физико-химические взаимодействия, которые могут приводить к образованию новых соединений, не образующихся в обычном (низкотемпературном) состоянии, например соединений из инертных газов. В зависимости от свойств плазмообразующей среды и условий реализации разряда состояние плазмы может иметь существенные различия. В частности, состояние плазмы может быть достаточно близким к состоянию термодинамического равновесия (квазиравновесие), а может быть далеким от него (неравновесная плазма). Поэтому плазмохимические системы иногда условно разделяют на два больших класса: неравновесные и квазиравновесные [4].

Наиболее широкие возможности с точки зрения реакционных взаимодействий имеет неравновесная плазма, в которой каждый сорт частиц и его состояние можно характеризовать своей температурой (например, температура электронов, температура ионов, вращательная температура, колебательная температура, температура заселения и др.). При этом „температура“ не является истиной термодинамической температурой, а является просто удобным параметром, позволяющим использовать при расчетах известные статистические функции распределения Максвелла, Больцмана, Саха, Планка и др. для соответствующего рода частиц. Эти температуры могут сильно отличаться друг от друга. В частности, в разряде низкого давления температура электронов в десятки тысяч градусов может быть в сотни раз больше температуры атомов и ионов (сотни градусов). В неравновесной плазме можно получить самые разнообразные химические вещества [3,4]. Как правило, неравновесная плазма получается при низких давлениях плазмообразующей среды $(P \leqslant 100 \mathrm{~mm} \mathrm{Hg})$ и небольших токах, а квазиравновесная - при высоких давлениях $(P \geqslant 1 \mathrm{~atm})[1-4]$. Часто для получения газоразрядной плазмы используют микроволновое излучение ISM-диапазона частот (915 MHz или $2.45 \mathrm{GHz})$.

В настоящее время создано довольно много конструкций СВЧ-плазмотронов различного назначения. Для большинства из них выбирается рабочая частота $2.45 \mathrm{GHz}$, широко применяемая в бытовых СВЧ-печах и промышленных установках [4]. Пример успешного использования СВЧ-плазмы для осаждения слоев кварцевого стекла, легированного фтором, на кремниевые подложки представлен в [5], где в качестве рабочей камеры СВЧ-плазмотрона был использован отрезок прямоугольного волновода сечением $72 \times 34 \mathrm{~mm}$. Данная PCVD-технология позволила достичь лучшей стехиометрии при образовании пленок оксида кремния по сравнению с другими известными методами. Аналогичная конструкция волноводного СВЧ-плазмотрона атмосферного давления с магнетронным источником энергии и рабочей частотой $2.45 \mathrm{GHz}$ была разработана в [6] для экспериментальных исследований процессов деструкции органических соединений в газовых и жидких средах. В качестве плазмообразующего газа в такой установке были использованы воздух и аргон. При этом расход угле- 

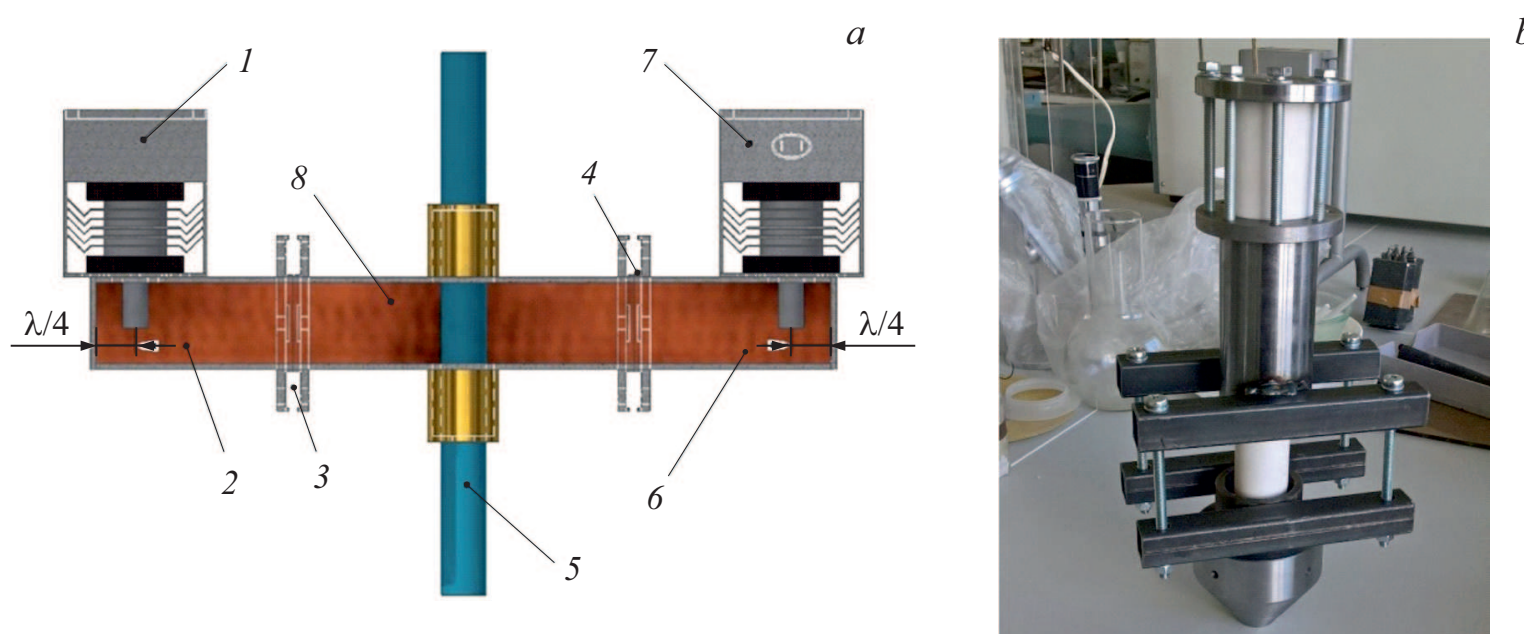

Рис. 1. $a-$ основные элементы конструкции СВЧ-плазмотрона: 1 - магнетрон; 2 - элемент ввода СВЧ-энергии электромагнитного поля; 3 и 4 - фланцевое соединение; 5 - разрядная трубка; 6 - элемент ввода СВЧ-энергии электромагнитного поля; 7 - магнетрон; 8 - рабочая камера. $b-$ рабочая камера и сопло плазмотрона.

водородного газа в экспериментах составил $0.4-1 \mathrm{~m}^{3} / \mathrm{h}$, а уровень СВЧ-мощности, подаваемой в область взаимодействия, варьировался в пределах $0.8-2 \mathrm{~kW}$. СВЧплазмотрон атмосферного давления для реализации новых пищевых технологий был создан в [7]. Особенностью его конструкции стало применение в качестве рабочей камеры тороидального резонатора с резонансной частотой $2449.3 \mathrm{MHz}$ и нагруженной добротностью 1200. Передача СВЧ-мощности от магнетрона в камеру осуществлялась с помощью волноводного перехода. При максимальной мощности источника $600 \mathrm{~W}$ высота плазменного факела составила $35 \mathrm{~mm}$, а плотность потока излучения вблизи установки не превысила $8.2 \mu \mathrm{W} / \mathrm{cm}^{2}$. Еще одна конструкция СВЧ-плазмотрона резонаторного типа была предложена в [8], где с ее помощью проводилось осаждение тонких алмазных пленок на силиконовые подложки. Сам MPCVD-реактор был выполнен в виде полуэллипсоида с металлическими ребрами. Данная конструкция позволила авторам [8] осуществить осаждение алмазных пленок со скоростью $3 \mu \mathrm{m} / \mathrm{h}$ на подложке диаметром примерно $5 \mathrm{~cm}$ при мощности магнетрона $6 \mathrm{~kW}$.

Примерами коммерческих СВЧ-плазмотронов атмосферной плазмы с частотой $2.45 \mathrm{GHz}$ являются плазмотрон компании НПП АгроЭкоТех (Россия) с регулируемой мощностью генератора до $3.5 \mathrm{~kW}$ и плазмотрон Surfaguide компании Sairem (Франция), особенностью которого является уменьшенная величина узкой стенки волноводного реактора.

Большинство рассмотренных и других известных конструкций СВЧ-плазмотронов выполняется по хорошо известной схеме и включает магнетрон с блоком питания, циркулятор с поглощающей нагрузкой, устройства подстройки и согласования, а также измерители падающей и отраженной волны, СВЧ-камеру. Такая схема компоновки не всегда обеспечивает необходимые режи- мы работы и в ряде случаев может привести к резкому поглощению СВЧ-мощности в области взаимодействия, а соответственно к нарушению работы плазмотрона.

В настоящей работе был разработан макет волноводного СВЧ-плазмотрона с двусторонним вводом электромагнитного поля [9]. Его конструкция показана на рис. $1, a$. Использование сразу двух источников излучения (магнетронов LG 2M213) позволяет более плавно управлять подачей СВЧ-энергии в зону нагрева, которая формируется газоразрядной трубкой из кварцевого стекла, размещенной в центре широкой стенки стандартного прямоугольного волновода сечением $90 \times 45 \mathrm{~mm}$. Расстояние от возбуждающего емкостного штыря каждого магнетрона до короткозамкнутой стенки волновода составляет $\lambda / 4$, где $\lambda$ - длина волны в волноводе в рабочем режиме плазмотрона (при наличии плазмы). Подача плазмообразующего газа (аргона) в область взаимодействия осуществлялась через фторопластовый штуцер.

Для решения проблемы транспортировки порошков, размеры частиц которых лежат в пределах 10-100 $\mu \mathrm{m}$, и их внесения в плазму был разработан пневматический дозатор [10]. При подаче аргона в бункер с порошковым материалом создается достаточно большое давление на единичную поверхность частиц порошка, приводящее к образованию взвеси в свободной части пространства бункера. Последующее вытеснение взвеси из бункера производится вновь поступившим количеством газа, а процесс становится непрерывным. Взвесь, состоящая из порошка и инертного газа, истекает под давлением в рабочую камеру (рис. $1, b)$, причем поток газа подается радиально к оси камеры, внутри которой образуются вихревые потоки. Дальнейший выход продуктов плазмохимического процесса осуществляется через сужающееся сопло (рис. 1,b). Рабочая камера плазмотрона 
выполнена из материала, обладающего незначительными диэлектрическими потерями в СВЧ-диапазоне.

Источники питания магнетронов были выполнены на трансформаторах, диодных столбах и конденсаторах, собранных по схеме однополупериодного удвоителя напряжения. Схема каждого источника состоит из двух анодных трансформаторов, включенных противофазно, и трансформатора для исключения перенапряжений на вторичных обмотках анодных трансформаторов во время включения.

Для определения выходной мощности магнетронов был разработан цифровой измеритель мощности на аппаратной платформе Arduino, базирующийся на калориметрическом методе определения температур.

Для инициирования разряда в кварцевой трубке в начальный момент времени использовался металлический пруток при максимальном уровне мощности каждого магнетрона. После пробоя газовой среды пруток извлекается, а дальнейшее поддержание разряда осуществляется за счет энергии электромагнитного поля.

Приняв допущение о том, что СВЧ-разряд представляет собой идеальный газ, состоящий из электронного и атом-ионного газа с различной температурой, определим состав плазмы для двухтемпературной системы с помощью уравнения Саха $[1,2]$ :

$$
\frac{\alpha^{2}}{1-\alpha^{2}}=\frac{2 g_{e} g_{i}}{g_{a}}\left(\frac{2 \pi m}{h^{2}}\right)^{3 / 2} \frac{\left(k T_{e}\right)^{5 / 2}}{p} \exp \left(\frac{e U_{i}}{k T_{e}}\right),
$$

где $\alpha$ - доля ионизированных атомов, $g_{e}, g_{i}$ и $g_{a}-$ квантовые статистические веса электрона, иона и нейтрального атома, $p$ - давление газа, $k-$ постоянная Больцмана, $U_{i}$ - потенциал ионизации молекулы газа, $h$ - постоянная Планка, $m-$ масса электрона, $T_{e}-$ температура электронов.

В том случае, когда $\alpha^{2} \ll 1, g_{e} \ll g_{i}$ и $g_{i}=g_{a}$, можно записать

$$
\alpha^{2}=2\left(\frac{2 \pi m}{h^{2}}\right)^{3 / 2} \frac{\left(k T_{e}\right)^{5 / 2}}{p} \exp \left(\frac{e U_{i}}{k T_{e}}\right) .
$$

Далее, решая уравнение Саха при заданных значениях $T_{e}, p, U_{i}$ и $\alpha$, можно найти электронную концентрацию и зависимость температуры электронов от величины напряженности электрического поля $E$ в волноводе. Расчеты показали, что зависимость $T_{e}(E)$ в интервале $1.25 \cdot 10^{4}<E<2.5 \cdot 10^{4} \mathrm{~V} / \mathrm{m}$ для стандартного прямоугольного волновода является линейной и температура электронов достигает величины $T_{e}=4 \cdot 10^{3} \mathrm{~K}$.

С помощью описанной установки (рис. 1,a) были проведены исследования рабочих режимов плазмотрона, разработана методика косвенного измерения температуры ионного газа и электронов, а также проанализированы процессы внесения порошкового материала $\mathrm{Cu}(50)$ в газоразрядный поток для формирования наноразмерных покрытий на поверхности твердых тел. В частности, было установлено, что поддержание разряда возможно даже одним работающим магнетроном при половине

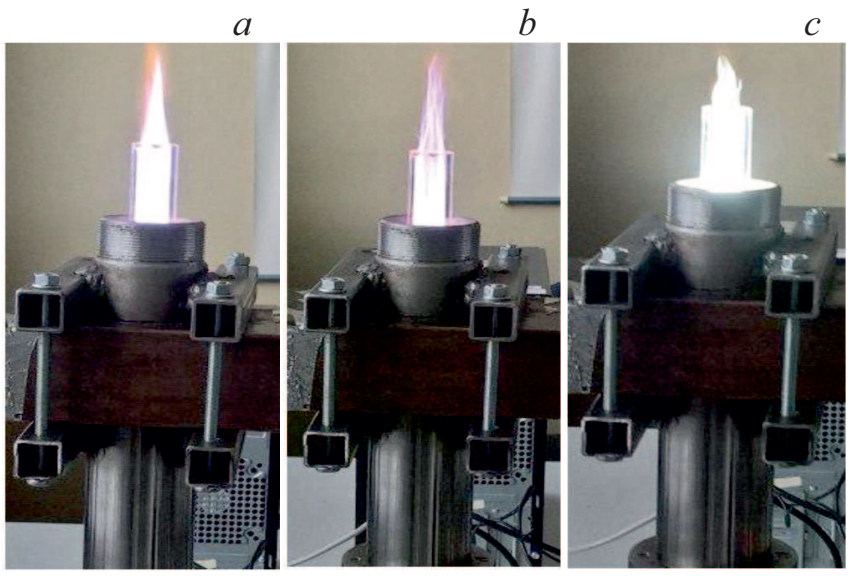

Рис. 2. Разряд СВЧ-плазмотрона в трех режимах его работы: выходная мощность обоих магнетронов составляет $600 \mathrm{~W}(a)$; выходная мощность первого магнетрона составляет $300 \mathrm{~W}$, а второго $600 \mathrm{~W}(b)$; выходная мощность первого магнетрона составляет $600 \mathrm{~W}$, а второй магнетрон отключен $(c)$.

периода напряжения питающей сети. Подобный режим работы приводит к образованию узких светящихся каналов ионизированного газа внутри разрядной трубки. В качестве примера на рис. 2 приведены фотографии плазменного факела в различных режимах работы магнетронов.

Кроме того, выяснилось, что устойчивый разрядный столб, сформированный внутри разрядной трубки, который по мере движения в камере не распадается на отдельные каналы, достигается за счет непрерывного ввода СВЧ-энергии в плазму, а также при расходе плазмообразующего газа свыше $31 / \mathrm{s}$.

Для оценки температуры инертного газа СВЧ-разряда при атмосферном давлении в качестве сенсора была использована хромель-алюмелевая термопара К-типа с погрешностью измерений до 1\% [11]. Измерение температуры разряда проводилось как на центральной оси факела, так и на удалении примерно $3 \mathrm{~mm}$ от центральной оси. При этом экспериментально было установлено, что при увеличении расхода плазмообразующего газа температура факела на выходе из трубки уменьшалась. На рис. 3 представлены результаты измерений, полученные для скорости потока воздуха 1.31 s.

Изучение процессов формирования наноразмерных покрытий, проведенное в настоящей работе, позволило выявить основные факторы, оказывающие влияние на морфологию этих покрытий, а также на механическое сцепление пленок с поверхностью подложки: способ введения порошка в зону нагрева, уровень мощности, подаваемой в разряд, расстояние между подложкой и выходным торцом газоразрядной трубки, физикохимические свойства порошка и подложки.

Проведенные эксперименты продемонстрировали, что внесение порошка вместе с газом ведет к оседанию порошка в виде пленки на внутренней поверхности 


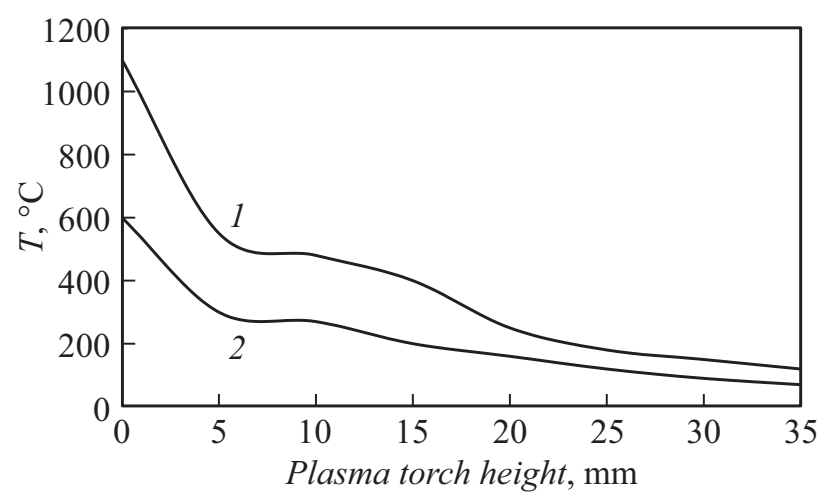

Рис. 3. Температура факела на его центральной оси (1) и вблизи внутренней поверхности кварцевой трубки (2) при расходе воздуха $1.31 / \mathrm{s}$.

газоразрядной трубки, что приводит к экранированию разряда от вводимого в плазму электромагнитного поля. При этом чем плотнее образованный слой, тем больше энергии возвращается в генератор, а разряд распадается на отдельные стримы.

Решение этой проблемы является одной из приоритетных задач предстоящих исследований.

Таким образом, созданный СВЧ-плазмотрон с двусторонним вводом излучения дает возможность получать достаточно стабильный разряд при минимальных затратах энергии, что в свою очередь открывает широкие перспективы усовершенствования технологий формирования покрытий различных материалов. Данный плазмотрон может быть полезен в экспериментальных исследованиях процессов взаимодействия микроволновой плазмы с различными веществами при разработке плазмохимических технологий в других сферах.

\section{Конфликт интересов}

Авторы заявляют, что у них нет конфликта интересов.

\section{Список литературы}

[1] B.M. Smirnov, Plasma processes and plasma kinetics (Wiley-VCH, N.Y., 2019).

[2] Encyclopedia of plasma technology, ed. by J.L. Shohet (CRC Press, N.Y., 2016), vol. 1, 2.

[3] Ю.Н. Туманов, Плазменные, высокочастотные, микроволновые $и$ лазерные технологии в химикометаллургических процессах (Физматлит, М., 2010).

[4] А.Н. Диденко, Б.В. Зверев, СВЧ-энергетика (Наука, М., 2000).

[5] Н.П. Зубков, Л.Ю. Кочмарев, И.П. Шилов, Электронная техника. Сер. 1. СВЧ-техника, № 3 (538), 64 (2018).

[6] А.Г. Жерлицин, В.П. Шиян, Л.Н. Шиян, С.О. Магомадова, Изв. Томск. политехн. ун-та, 326 (10), 65 (2015).

[7] А.В. Прокопенко, К.Д. Смирнов, Прикладная физика, № 5, 64 (2011).
[8] J.J. Su, Y.F. Li, X.L. Li, P.L. Yao, Y.Q. Liu, M.H. Ding, W.Z. Tang, Diamond Relat. Mater., 42, 28 (2014). DOI: 10.1016/j.diamond.2013.12.001

[9] И.Н. Антонов, А.Н. Пименов, Плазмотрон с двусторонним вводом энергии электромагнитного поля в поток газа, патент РФ № 198579 (2020), БИ № 20.

[10] И.Н. Антонов, А.Н. Пименов, Порционный дозатор порошковых материалов для нанесения газотермических покрытий, патент РФ № 172620 (2017), БИ № 20.

[11] О.В. Карабчевская, А.В. Прокопенко, К.Д. Смирнов, В сб.: Междунар. конф. по физике плазмы (ПЛАЗМАИОФАН, M., 2012), c. 216. 